\title{
Characterization of Thin Carbon Films Produced by the Magnetron Sputtering Technique
}

\author{
Danilo Lopes Costa e Silva ${ }^{a *}$, Luciana Reyes Pires Kassab ${ }^{b}$, Jose Roberto Martinelli ${ }^{a t}$, \\ Antonio Domingues dos Santos ${ }^{c}$, Sidney José Lima Ribeiro ${ }^{d}$, Moliria Vieira dos Santos ${ }^{d}$ \\ ${ }^{a}$ Nuclear and Energy Research Institute, SP, Brazil \\ ${ }^{b}$ Faculty of Technology of São Paulo - FATEC-SP, SP, Brazil \\ ${ }^{c}$ Institute of Physics, University of São Paulo - USP, SP, Brazil \\ ${ }^{d}$ Institute of Chemistry, São Paulo State University - UNESP, \\ CP 355, 14801-970, Araraquara, SP, Brazil \\ In memorian
}

Received: January 21, 2015; Revised: March 22, 2016; Accepted: April 4, 2016

\begin{abstract}
Thin carbon films containing both amorphous and crystalline structures were produced by RF magnetron sputtering. The depositions of the carbon films were performed on Co buffer layers previously deposited on c-plane (0001) sapphire substrates. The thin carbon films were characterized by high-resolution transmission electron microscopy (HRTEM), X-ray diffraction (XRD), Raman spectroscopy, energy dispersive X-ray spectroscopy (EDS), and field emission scanning electron microscope (FEG-SEM). The Raman spectra confirmed the presence of amorphous and crystalline structures by the existence of an intense $\mathrm{D}$ band separated from the $\mathrm{G}$ band, indicating early stages of crystallization. The interplanar distance corresponding to the graphite structures was determined by using HRTEM micrographs.
\end{abstract}

Keywords: Carbon films, Graphene, Sputtered carbon, Graphite

\section{Introduction}

Carbon films attract the scientific interest because of their unusual structure and properties. They are typically denser, tougher and more resistant to chemical attacks than any other hydrocarbon or solid carbonaceous polymer ${ }^{1}$. Graphene is a monolayer of carbon atoms arranged in a hexagonal lattice, and has attracted a great interest because of its unique structure and promising properties ${ }^{2}$. It is extremely strong with a reported breaking strength of about $40 \mathrm{~N} / \mathrm{m}$ and Young's modulus of about $1 \mathrm{TPa}^{3}$. It also exhibits flexibility, it can crinkle and bend ${ }^{4}$. The presence of strains in graphene can induce a pseudo-magnetic field greater than $300 \mathrm{~T}^{5}$ and also changes its electronic structure ${ }^{6}$. The growth of graphene cannot be described by a universal mechanism with specific routes and conditions. Actually, there is a variety of synthesis strategies and growth modes ${ }^{7}$. A good mechanism for its growth is the use of metal catalysts on which free carbon radicals are formed, carbon is dissolved in the catalyst, and finally precipitates and crystallizes at the surface ${ }^{8}$. It has been observed that an amorphous carbon film is taken up by $\mathrm{Fe}, \mathrm{Co}$, or Ni films at temperatures above $600^{\circ} \mathrm{C}^{9}$. The nucleation and subsequent growth of graphene layers on the catalyst metal occur after the dissolution of the amorphous carbon film. The literature reports that the transformation of amorphous carbon to graphene occurs by diffusion of carbon atoms through the catalyst metal ${ }^{9}$. The synthesis of graphene by epitaxial growth on transition metals has been previously reported ${ }^{10-13}$.

* e-mail: dalocsfl@usp.br
It has been observed that thin films produced by other processes such as chemical vapor deposition (CVD), are highly pure and present good quality crystal structures. However, the film stoichiometry and adhesion to the substrate is quite poor. On the other hand, high purity films cannot be produced by sputtering techniques because of the contaminated species in the plasma, which can be simultaneously deposited on the substrate, but good film adhesion to substrates can be obtained and the target stoichiometry is maintained in the deposited films. Such characteristics are achieved when co-deposition techniques (doping the films with other materials) are used.

Raman spectroscopy is one of the best-known techniques for graphite/graphene characterization. Raman spectra obtained from different regions of a carbon film deposited by magnetron sputtering showed 5 stages $^{13}$ of growing crystallization. The first stage refers to the presence of disordered carbon atoms, the second one indicates a higher degree of crystallinity; the third one refers to single-crystalline graphite, the fourth one to the double layer graphene, and finally the fifth and last one to monolayer graphene ${ }^{13}$. These spectra, when overlaid, show that there is a reduction in the $\mathrm{D}$ band, a narrowing, and intensity increase in the $\mathrm{G}$ band, and the arising of the 2D band, as the film crystallizes from amorphous to the monolayer graphene ${ }^{13}$.

In this work, the deposition of thin carbon film by magnetron sputtering on Co buffer layer previously deposited on heated sapphire substrates was performed aiming to obtain graphene layers. 


\section{Materials and methods}

\subsection{Deposition}

The carbon/cobalt depositions were performed using an ATC 2000 Sputtering System (Aja International equipment) by DC magnetron sputtering technique from a $99.999 \%$ pure Kurt J. Lesker graphite target, and a $99.99 \%$ pure cobalt target, respectively. The substrate was sapphire orientated on c-plane (0001), $1 \times 1 \mathrm{~cm}^{2}$, and the substrate/target distance was kept at $15 \mathrm{~cm}$. The rotating substrate-holder was kept at $600^{\circ} \mathrm{C}$ by thermal radiation from internal incandescent lamp bulbs during the whole process. The pressure before inserting a mixture of Ar and $5 \%$ of $\mathrm{H}_{2}$ was $2 \times 10^{-7}$ Torr. The deposition of Co was carried out during 16 minutes, with the DC power supply set to $100 \mathrm{~W}$, working pressure of $5 \mathrm{mTorr}$ and gas flow of $20 \mathrm{sccm}$. For the $\mathrm{C}$ deposition, during 1 hour, the DC power was $150 \mathrm{~W}$, the working pressure was $15 \mathrm{mTorr}$ and the gas flow was $40 \mathrm{sccm}$. A heat treatment was performed in a Lindberg/Blue tube furnace under a $2.85 \times 10^{-5}$ Torr, using an Oerlikon Leybold vacuum Pump System PT50, during 10 minutes at $850{ }^{\circ} \mathrm{C}$.

\subsection{Characterization}

The morphological characterization of the samples was performed using a field emission gun scanning electron microscope (FESEM, JEOL JSM-7500F), and a high-resolution transmission electron microscope (HR-TEM JEOL 3010), $300 \mathrm{kV}$ with $\mathrm{LaB}_{6}$ filament). The structural characterization was performed by a Miniflex II Rigaku X-Ray Diffractometer equipment with $\mathrm{K} \alpha_{\mathrm{Cu}}$ radiation and the Raman spectroscopy by a HORIBA JOBIN-YVON model LabRAM HR 800 spectrometer, operating with laser $\mathrm{He}-\mathrm{Ne} 632.81 \mathrm{~nm}$ with a CCD camera model DU420AOE-325.

For the measurement of the carbon thin film thickness it was used the Rutherford Backscattering Spectrometry (RBS) and the Nuclear Reaction Analysis (NRA) for the nuclear reaction $12 \mathrm{C}(4 \mathrm{He}, 4 \mathrm{He}) 12 \mathrm{C}$, at the alpha beam energy of $4.256 \mathrm{MeV}$. The spectrum was analyzed with the aid of the SIMNRA ${ }^{15}$. This measurement was performed for a carbon film produced with the same deposition conditions described above (C deposition during $1 \mathrm{~h}$ with RF power of $150 \mathrm{~W}$ ) on (100) Si substrate and it was obtained $2.6 \mathrm{~nm}$ for the $\mathrm{C}$ thickness.

\section{Experimental results and discussion}

\subsection{Morphological studies}

Figure 1 shows the FEG-SEM micrograph of one of the carbon/cobalt deposited sample on a c-plane (0001) sapphire substrate, keeping the substrate heated, as previously described. The partial coalescence of Co grains can be seen.

\subsection{HRTEM and EDS}

High-resolution transmission electron micrographs (HRTEM) are shown in Figures 2a and $2 b$ of two different regions of the $\mathrm{C} / \mathrm{Co}$ surface after heat treatment. In Figure 2a, crystalline structures (red circles) related to the cobalt film can be seen. The method used for the preparation of the sample for the HRTEM was based on scrapping the sample with a quartz point and depositing it on the HRTEM grid. Figure $2 \mathrm{~b}$

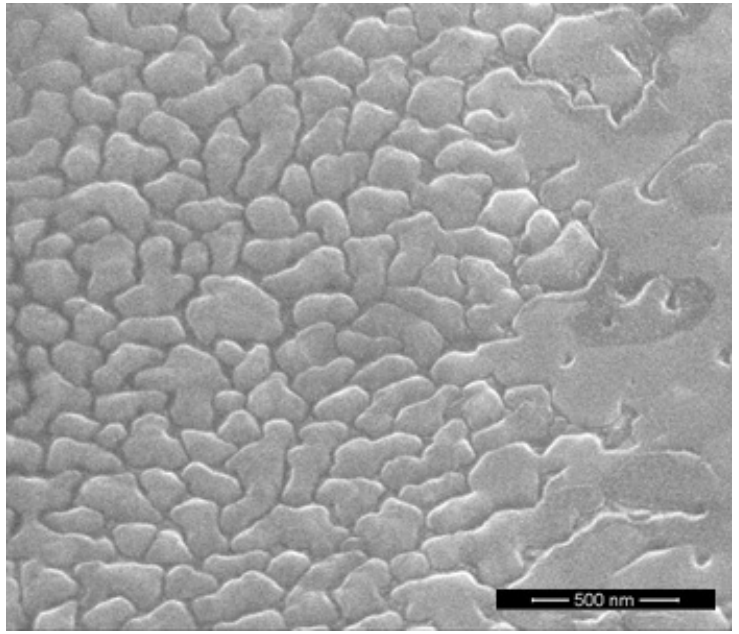

Fig.1 - FEG-SEM micrograph of the sample deposited on c-plane (0001) sapphire substrates, heated at $600{ }^{\circ} \mathrm{C}$ and with working pressure of $15 \mathrm{mTorr}$ showing Co islands randomly distributed and some are interconnected.

shows a material that has been reported in the literature ${ }^{14}$ as "Onion-Like-Carbon (OLC)", where several carbon planes are rolled forming a circular structure, which resembles an onion with its concentric layers. The curving and closure of these newly formed graphitic planes occurs to minimize their surface energy ${ }^{14}$. Figure $2 \mathrm{c}$ shows the EDS spectrum of the "Onion-Like-Carbon" structures (Figure 2b). The intense carbon peak confirms the composition of the "onion-like" structures. The presence of a $\mathrm{Cu}$ peak is related to the grid used for HRTEM measurements. $\mathrm{O}$ and Si peaks are probably due to contamination during the sample preparation for HRTEM measurements. The interplanar distance shown in Figure $2 b$ was measured by the use of the ImageJ software. The obtained value is in the range of 0.345 to $0.350 \mathrm{~nm}$ and corresponds to the interplanar distance of graphite, as previously reported in the literature.

\section{3 - Films' crystallinity}

The crystallinity of the carbon film was investigated by the XRD measurements. In the XRD pattern shown in Figure 3 , there is a peak at $\sim 2 \theta=26.5^{\circ}$ (ICSD 01-089-8487) that can be associated to the presence of graphite structures. There is also a peak related to the sapphire substrate $\left(\mathrm{Al}_{2} \mathrm{O}_{3}\right)$ at $2 \theta=20.5^{\circ}$ (ICSD 01-073-1199). The XRD measurements were conducted in the theta-2theta configuration and the results corroborates the Raman spectra (see next section), where there is a band related to crystalline carbon films and another band to amorphous ones.

\section{4-Raman spectroscopy}

Figure 4 shows the Raman spectrum corresponding to the carbon film deposited on sapphire substrate heated at $600{ }^{\circ} \mathrm{C}$ and working pressure of $15 \mathrm{mTorr}$.

Comparing the spectra previously reported ${ }^{13}$ with those obtained in the present work, it can be seen that the film deposited under $15 \mathrm{mTorr}$ is in the initial stage of crystallization. In this stage, the D band (vibrational mode of amorphous 


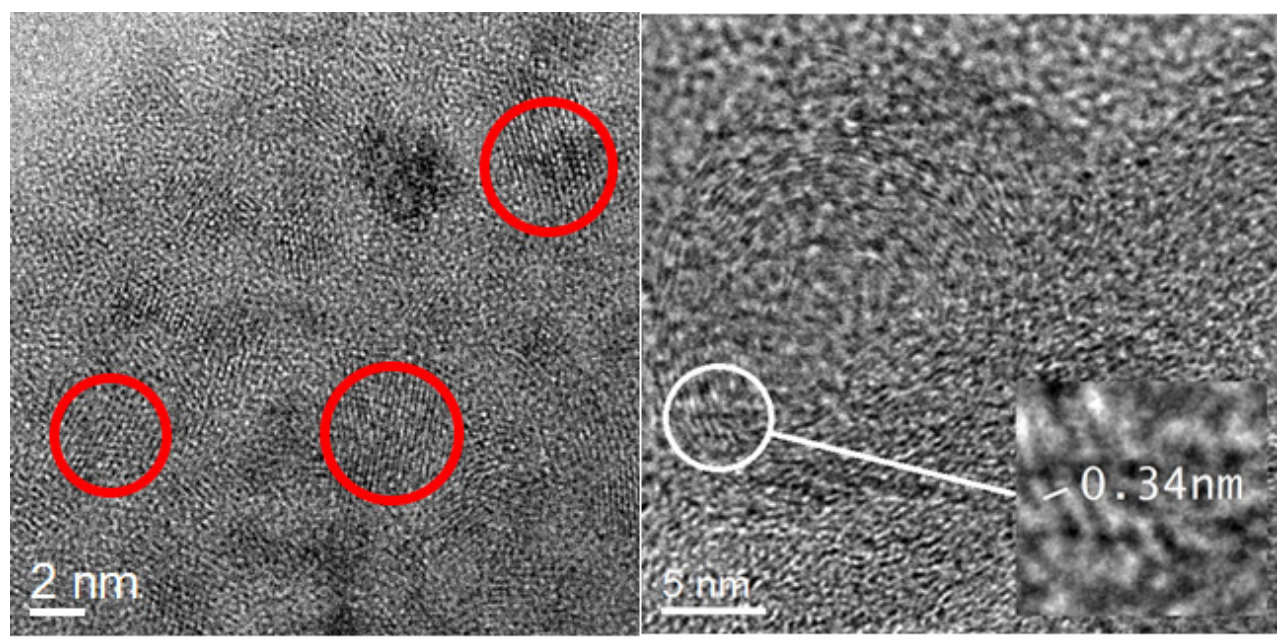

Figure 2a

Figure $2 b$

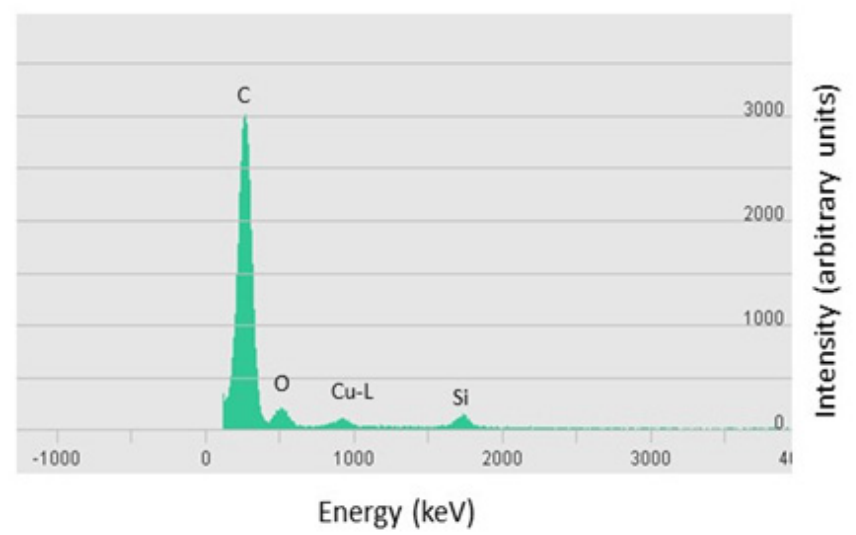

Figure 2c

Fig. 2 - (a) HRTEM image of the sample treated in high vacuum showing crystalline structures related to cobalt randomly distributed; (b) HRTEM image of another region of the sample, where there is the presence of "Onion-Like-Carbon" structures; (c) EDS spectrum of the structures shown in Figure $2 b$.

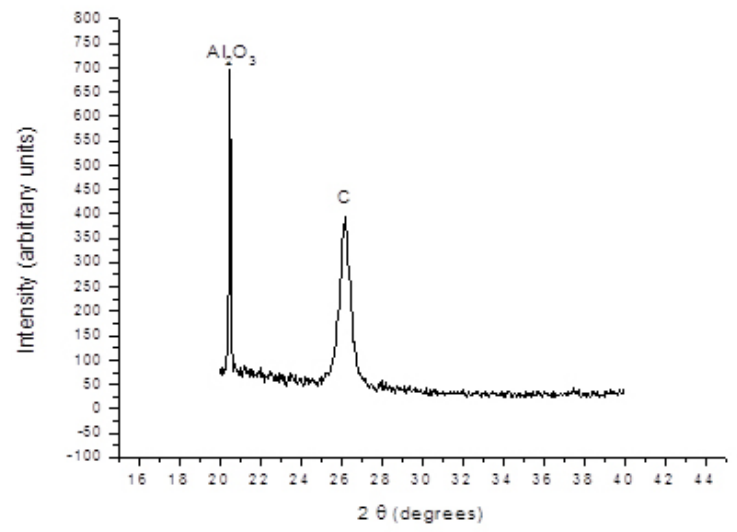

Fig. 3 - X-Ray diffraction pattern of the sample that underwent heat treatment in vacuum, at $850^{\circ} \mathrm{C}$ for 10 minutes.

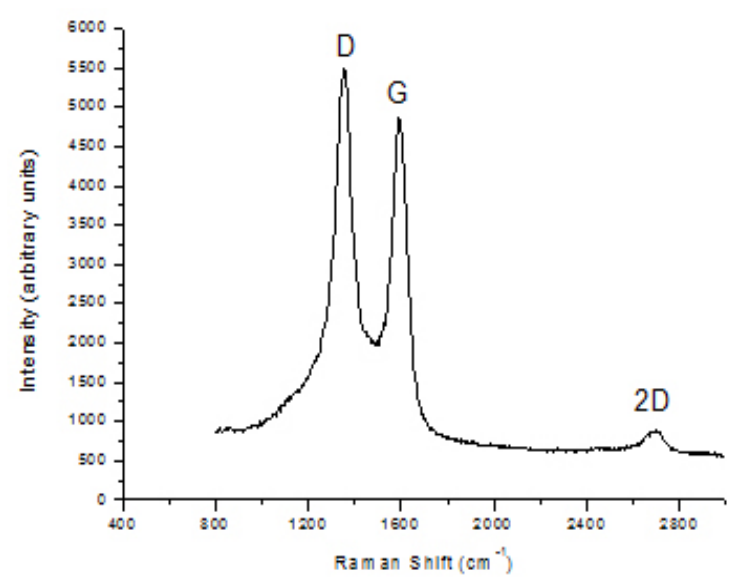

Fig. 4 - Raman spectrum of the carbon thin film. 
carbon) is more intense than the $\mathrm{G}$ band (vibrational mode of ordered carbon), and the 2D band that normally appears for graphite and graphene films, being much more intense than $\mathrm{G}$ band for the monolayer graphene structure. Normally, the $2 \mathrm{D}$ and $\mathrm{G}$ bands have the same intensity for bilayer graphene structure.

\section{Conclusions}

In this work, evidences are shown that carbon films deposited by magnetron sputtering on Co buffer layers previously deposited on heated sapphire substrates present amorphous and crystalline regions. This could be confirmed by the Raman spectrum that shows the $\mathrm{D}$ band related to amorphous carbon, but also the G and 2D bands related to crystalline carbon structures. The XRD patterns evidenced the presence of graphite and the HRTEM micrographs indicated the presence of graphite planes and OLC structures whose interplanar distances were measured. There is a strong

\section{References}

1. Amorim HA. Caracterização de filmes finos de carbono depositados por PECVD, [Dissertation]. Campinas (SP): UNICAMP; 1995.

2. Geim AK, Novoselov KS. The rise of graphene. Nature Materials. 2007;6:183-191. http://dx.doi.org/10.1038/nmat1849

3. Lee C, Wei X, Kysar JW, Hone J. Measurement of the elastic properties and intrinsic strength of monolayer graphene. Science. 2008;321(5887):385-388. http://dx.doi.org/10.1126/ science. 1157996

4. Booth TJ, Blake P, Nair RR, Jiang D, Hill EW, Bangert U, et al. Macroscopic graphene membranes and their extraordinary stiffness. Nano Letters. 2008;8(8):2442-2446. http://dx.doi. org/ 10.1021/n1801412y

5. Levy N, Burke SA, Meaker KL, Panlasigui M, Zetti A, Guinea F, et al. Strain-induced pseudo-magnetic fields greater than 300 tesla in graphene nanobubbles. Science. 2010;329(5991):544547. http://dx.doi.org/10.1126/science.1191700.

6. Huang M, Yan H, Heinz TF, Hone J. Probing Strain-induced electronic structure change in graphene by Raman spectroscopy. Nano Leters. 2010;10(10):4074-4079. http://dx.doi.org/10.1021/ n1102123c

7. Subrahmanyam KS, Vivekchand SR, Govindaraj A, Rao CN. A study of graphenes prepared by different methods: characterization, properties and solubilization. Journal of Materials Chemistry. 2008;18(13):1517-1523. http://dx.doi.org/10.1039/B716536F

8. Barreiro A, Börrnert F, Avdoshenko SM, Rellinghaus B, Cuniberti G, Rümmeli MH, et al. Understanding the catalystfree transformation of amorphous carbon into graphene by motivation for further research to obtain graphene, by adjusting the parameters used for magnetron sputtering. This process may become an alternative method for the production of crystalline carbon films, controlling the number of layers of graphene films, in order to use them in advanced scientific researches and applications.

\section{Acknowledgements}

This work was supported by the National Institute of Photonics (INCT de Fotônica) project granted by the Conselho Nacional de Desenvolvimento Científico e Tecnológico - CNPq. We would like to thank FAPESP, Laboratório Nacional de Nanotecnologia do Centro Nacional de Pesquisa em Energia e Materiais, for the HRTEM measurements and Laboratório de Materiais e Feixes Iônicos do Instituto de Física da USP for the RBS/NRA measurements.

current-induced annealing. Science Reports. 2013;1115. http:// dx.doi.org/10.1038/srep01115

9. Rodríguez-Manzo JA, Pham-Huu C, Banhart F. Graphene growth by a metal-catalyzed solid-state transformation of amorphous carbon. ACS Nano. 2011;5(2):1529-1534. http:// dx.doi.org/10.1021/nn103456z

10. N'Diaye AT, Bleikamp S, Feibelman PJ, Michely, T. TwoDimensional Ir Cluster Lattice on a Graphene Moiré on $\operatorname{Ir}(111)$. Physical Review Letters. 2006;97(21):215501. http://dx.doi. org/10.1103/PhysRevLett.97.215501

11. Marchini S, Gunther S, Wintterlin J. Scanning tunneling microscopy of graphene on Ru (0001). Physical Review B. 2007;76(7):075429. http://dx.doi.org/10.1103/PhysRevB.76.075429

12. Vazquez de Parga AL, Borca FC, Passeggi MC Jr, Guinea JJ, Miranda R. Periodically rippled graphene: growth and spatially resolved electronic structure. Physical Review Letters. 2008;100(5):056807. http://dx.doi.org/10.1103/ PhysRevLett.100.056807

13. Yurkov AN, Melnik NN, Sychev VV, Savrans VV, Vlasov DV, Konov VI. Synthesis of carbon films by magnetron sputtering of a graphite target using hydrogen as plasma-forming gas. Bulletin of the Lebedev Physics Institute. 2011;9:263.

14. McDonough JK, Gogotsi Y. Carbon onions: synthesis and electrochemical applications. The Electrochemical Society Interface. 2014:23(1):61-65.

15. Mayer M. SIMNRA, a simulation program for the analysis of NRA, RBS, and ERDA. In: AIP Conference Proceeding. 1999;475:541-544. 